\title{
Modernity, method and minimal means: typewriters, typing manuals and document design
}

Article

Accepted Version

Walker, S. (2018) Modernity, method and minimal means: typewriters, typing manuals and document design. Journal of Design History, 31 (2). pp. 138-153. ISSN 1741-7279 doi: https://doi.org/10.1093/jdh/epx018 Available at https://centaur.reading.ac.uk/69514/

It is advisable to refer to the publisher's version if you intend to cite from the work. See Guidance on citing.

To link to this article DOI: http://dx.doi.org/10.1093/jdh/epx018

Publisher: Oxford University Press

All outputs in CentAUR are protected by Intellectual Property Rights law, including copyright law. Copyright and IPR is retained by the creators or other copyright holders. Terms and conditions for use of this material are defined in the End User Agreement.

www.reading.ac.uk/centaur

\section{CentAUR}


Central Archive at the University of Reading

Reading's research outputs online 


\section{Modernity, method and minimal means: typewriters, typing manuals and document design}

This essay is about the contribution that typing manuals and typists have made to the history of graphic language and communication design, and the role that typewriter composition has played in typographic education and design practice, particularly in the 1960 s and 1970s. The limited technical capabilities of typewriters are discussed in relation to the rules in typing manuals for articulating and organising the structure of text. Such manuals were used to train typists who went on to produce documents of considerable complexity within what typographers would consider to be minimal means in terms of flexibility in the use of letterforms and space.

Key words: typewriter composition, document design, typography, technology

\section{Introduction}

At the beginning of the twentieth century typewriters were part of the modern office: new machines operated by women and men who had a thorough training in how to use them and in how to format and produce different kinds of document. ${ }^{1}$ Typing manuals and the relentless repetition of typing exercises in class formed the basis of this training, and generations of office workers acquired considerable knowledge about the visual organisation of often complex documents. In the context of the history of typography, typewriter operators (typists as they became known) were designing within 'minimal means'. They worked with a restricted range of letterforms and character sets; and with limited flexibility for manipulating vertical and horizontal space. The documents they made - in their material form - were true to the limitations of the machines that made them. Designers and educators also exploited the characteristics (and limitations) of typewriters in their work; in the 1950s and 1960s especially, typewriters were regarded by designers as one of the tools of the trade, though perhaps, as Ken Garland (1962: 66) has noted 'a design tool that is not usually regarded as such'. Design educators such as Norman Potter and Michael Twyman used the limitations of typewriter composition to good effect in teaching typography. And because typing manuals were concerned with the kind of document that Herbert Spencer, in 1952, called 'utility' printing ('technical catalogues, handbooks, timetables, stationery and forms, the primary purpose of which is to inform'), the typewriter as the means of production for such documents has a place in the history of document design and, by 
inference, of information design. ' 'Typewriter composition' was prevalent in the printing trade in the 1960 s and 1970 s and many typists who trained on mechanical typewriters went on to become 'compositors' working with electric machines such as the IBM 72, the IBM Executive, the Justowriter and later models of the Varityper. ${ }^{3}$ In this context typists assumed the role of compositor, applying rules acquired through typing training to typesetting in books.

\section{Minimal means and a user-driven approach}

Typewriters and the manuals that gave instructions for their use led to the rise of a user-driven approach to the design of functional documents, an approach influenced by the means of production. Richard Southall (1984: 83) used the term 'graphic capability' (of a typesetting system) to refer to the potential for articulation of document structure, describing it as constrained by 'the number of characters, typefaces, and type sizes and the facilities for defining amounts of horizontal and vertical space, that the system offers'. Graphic capability, then, is determined by the size of the character set and the finesse by which vertical and horizontal space can be manipulated. The graphic capability of the typewriter is severely limited. Yet it is these limitations that connect with modernist design principles. As noted by McIntosh (1965: 69): 'With only one typeface and size, with uniform inter-line and inter-word spacing and no justification, the typewriter is ... ideal, also because of its cheapness and simplicity of operation and ubiquity.'

Histories of typewriters tend to focus on mechanical details and the engineering complexity (for example, Mares 1909; Richards 1964).4 These pay little attention to the content of the manuals that explained how they should be operated and used in the context of producing documents. This paper focusses on the latter and presents rules and prescriptions for organising text, essentially principles of layout and house style that are found in typing manuals. The prescriptions given are made in relation to commercial and business office documents. Many of the rules define basic typographic principles even though there is not the range of letterform variation or spatial flexibility that is available in conventional typesetting systems. So, what were the rules and conventions that were presented in typing manuals? What did trainee typists learn about making documents? What influence have typewriters had on document design?

Typing manuals 
Towards the end of the nineteenth century, most office work was done in copperplate script or a variant of copperplate handwriting known as the 'Civil Service hand', 5 and followed precise rules, an example being the setting out of correspondence. The transition to typewriters must have been challenging, both technically and stylistically, and the author of an 1893 manual showed 'a specimen of typewriting illustrating, in perhaps an exaggerated form, most of the irregularities to be found in unskilled work'. (Pitman 1893: plate 1). Many of these irregularities were explained as the ineffective technical use of the typewriter, such as uneven impression, and the misuse of one character for another, but reference to irregular spacing and uneven margins reflected a concern for elementary principles of typography that were relevant to making documents easy for people to read.

Manuals to provide instruction in typing skills began to appear in the 1880 s. One of the earliest was John Harrison's A manual of the typewriter, published by Isaac Pitman in 1888. Others followed, often connected to a particular typewriter brand, such as Instructions on the Calligraph typewriter (1891). The 1890 s and early 1900 saw the publication of what quickly became 'standard works' that ran to many editions: Pitman's A manual of the typewriter was first published in 1893, with numerous editions up to 1922, when it was superseded by Pitman's commercial typewriting, which was published until $1977 .{ }^{6}$ Prominent twentieth-century authors of similar wellregarded manuals were Arthur E. Morton, Edith Collyns, Edith R. Smith, Frederick Heelis, Maxwell Crooks, William and Elizabeth Walmsley and Edith Mackay.7 A detailed survey of rules for visual organisation in key typing manuals in numerous editions showed consistency in content, though with change over time reflected across editions. Such change, for example in relation to conventions for abbreviation, reflects the evolution of language through micro typographic articulation (Walker 2001).

Typing manuals contained rules and conventions, in the main, for commercial correspondence and related office work, but many also included sections on setting out plays, engineering specifications, and legal documents, each with facsimiles as examplars. Information presented ranged from punctuation, grammar and style, to postal regulations and forms of address. The early typing manuals prescribed conventions derived from commercial handwriting practice, as would have been prevalent in office work (such as the use of superior figures in dates), and others were influenced by the desire to emulate typesetting and to reflect formality and authority (such as centring and capitalisation). 
Typing manuals formed the basis for the attainment of skills necessary for being an efficient office worker. Most were progressive, beginning with fingering exercises and ending with the transposition of handwritten material into typed documents in accordance with typing rules and conventions that would have been mastered along the way. The attainment of skills was reinforced through examinations and certificates. In the manuals the words 'display' and 'setting out' were used frequently, suggesting that visual or artistic ability was a required skill. Typists were also expected to know how to spell, punctuate and organise text into paragraphs. The rules covered issues of organising text on a micro level, such as punctuation, use of capital letters and treatment of book titles - all issues referred to by printers as 'house style'. Keeler in The Phonetic Journal in 1904: 836 observed:

Style in commercial typewriting, in contradistinction to 'style' in literary work, may be defined as the due observance of particular rules or principles, more or less wellknown, in the technical setting out or rendering of any MS. into print, or typewriting and conformity with certain 'niceties' in the mode of arranging commercial terms, phrases, abbreviations, figures; careful attention to paragraphing, spaces after punctuation marks, etc.

Typing manuals therefore provide an excellent repository of codified practice - rules and principles relevant to typewriter composition. Typists, through engagement with the manuals, became experts using a text composition system with limited graphic capability. The skills they acquired influenced the visual organisation of everyday documents seen, for example, in the mapping of prescription to practice in a survey of late nineteenth- and early twentieth-century typed correspondence in the archives of the publisher, Macmillan and the agricultural machinery company, Nalder \& Nalder (Walker 1984), and in relation to business memos (Yates and Orlikowska 1992).

The rest of this essay summarises how typing manuals presented elementary typographic principles and conventions. It begins with letterforms, then use of horizontal and vertical space and differentiation of elements within text, drawing on information from some of the widely-used typing manuals and focusing on those elements that are particularly relevant to elementary typographic design. Tabular matter is mentioned briefly as an example of the more complex text composition that typing manuals covered. Following this, there are reminders of the contribution that typewriter composition has made to document design and to typographic education.

\section{Document design}




\section{The character set}

Most typists, in training or working in an office or typing pool, were assigned a typewriter with a single, built-in type style such as one of those illustrated in Figure 1, and most typing manuals published in the early years of the twentieth century included examples of styles of typewriter type. ${ }^{8}$ The most widely used was 'Roman' according to Arthur E. Morton who also illustrated other typewriter type styles for particular purposes, including Medium Roman, 'a favourite type with clergymen and public speakers', and Gothic, which was 'very clear, inasmuch as it consists wholly of large and small capitals. It is much used for presswork and by engineers where a large number of special fractions are required.' (Morton 1902: 34). 'Large Roman' was described as: 'large and clear, and can be advantageously used when these qualities are a desideratum.' Because a standard typewriter character set was limited to capitals, small letters, punctuation marks, numbers and some fractions, and some commercial signs such as @, \& and \%, part of the training to be a typist was learning how to combine characters to make new ones (Figure 2). For specialist work, such as for languages with accents, and work that contained fractions, there were machines with special keyboards, such as '64th Fraction Keyboard', described as a 'specimen of the work of the Smith Premier typewriter fitted with "gothic" type and a special arrangement of keyboard by which a large number of characters can be written' (Morton 1902: 50).

\section{Line spacing and word spacing}

Space between lines was effected by a carriage lever attached to a ratchet that turned the platen. The carriage lever usually turned the platen two notches - equivalent to single-line spacing; two pushes of the lever resulted in double-line spacing and so on. A half-line space was the result of turning the platen manually by a single notch. Prescriptions for line spacing in the early manuals were rather complex for what might appear to be a relatively straightforward matter given the limited number of options. Trainee typists were urged to take a number of factors into account, including taste, cost, and document kind and length. Figure 3 illustrates kinds of usage under single, double or treble line spacing. The rules in Pitman's typewriter manual (1897: 33) were less precise:

One-spacing should only be adopted when economy is a consideration, or when, for other reasons, it is desirable that the matter should occupy as little space as possible. Two-spacing is usual, and certainly gives the best results. Threespacing is general used only in display work, or in addressing envelopes. The 
lines may be separated even more widely in the case of a piece of work displayed throughout.

Typing manual authors explained how line spacing could be used to define hierarchy within a text, echoing standard typographic practice though with much cruder vertical increments. Edith Collyns (1909: 142) provided a succinct verbal explanation:

Leave a wider line-space after the heading that than employed between the lines in the body of the work; thus, if double line-spacing be employed in the body of the work, employ not less than three after the heading.

If there is a heading and a sub-heading, separate the heading from the sub-heading by a greater space than the sub-heading from the body of the matter...

Sometimes prescriptions for particular usage of vertical space were associated with a document type, such as a specification where, for example, Collyns (1909: 149) instructed: 'Employ double line spacing; treble between paragraphs and four between the main parts, or if preferred, single, double, and treble.'

Typing manuals contained different rules for using horizontal space between punctuation marks and in so doing created a hierarchical system of differentiation between parts of a sentence. The earliest manuals published by Pitman, for example, recommended three spaces after a full stop, two spaces after a colon and a semi-colon and one space after a comma. Other manuals, such as Morton's Modern typewriting and manual of office procedure (1902) preferred two, rather than three, spaces after a full stop, and this practice continued until the present day. ${ }^{9}$ Few manual authors go into detail as to why large spaces should be left at the end of sentence, though it does follow typesetting practice in the late nineteenth and early twentieth century (such as in children's books). ${ }^{10}$ As with many of the rules that typists had to learn one cannot help thinking that incremental word spacing, particularly of the 3, 2, 1 kind, was included as a particular challenge for trainee typists.

\section{A fixed character width}

A ragged right-hand edge was an inevitable and distinctive visual attribute of typewritten documents. This feature might be described as informal, relative to books and journals. ${ }^{11}$ It prevailed because justifying lines on a typewriter, though not impossible, was difficult:

... a completely even, or 'justified', right-hand margin is not possible with most typewriters - unless the space between the words is adjusted to ensure that the 
lines all end at the same point. For this purpose a draft must, of course, be typed. When retyping, the first line should be the required length and the spaces between the words should be suitable adjusted on subsequent lines so that they end flush with the first line. Obviously, such a procedure is very timeconsuming and could only be recommended for the production of originals for high-class work. (Mackay 1977: 117-8)

Nevertheless, since the end of the nineteenth century and driven by commercial imperatives, there were attempts to make typewriters that could justify lines through the use of proportional character width and proportional spacing. ${ }^{12}$ From the 1920 s the Varityper was one kind of typewriter used to produce justified lines; it relied on typing the text twice:

When first typed, each line must finish with a justification space, as shown on a dial on the machine. This space is adjusted before the second typing by a special device which automatically and evenly distributes the justification space so that the line ends are equal. (Mackay 1977: 233) ${ }^{13}$

Many short-run book publishers, for reasons of economy and flexibility, were keen to use typewriter composition for artwork for printing by offset lithography. Justified setting was integral to this. For some 'to publish a ragged-right book was considered to be more daring than to print with sans-serif typefaces'. (Jamison 1998: 82). And this notion - that justified setting was 'correct' for book publishing - was a widely-held view. An example of a typewriter-composed book with a justified right-hand edge was written and produced (probably on a Varityper) by a chemist, Cyril Tyler, in the 1940 s at the University of Reading (Figure 4). Tyler used a typewriter to compose his book for reasons of cost and because he was very particular about the setting out of formulae and equations. A note inserted in the book details that it was typed on a 'large image typewriter' - and then justified in a way that involved a second typing; superior and inferior figures and the formulae lines were, he said, added by artists according to his instructions, following an underlying grid. ${ }^{14}$

Other publishers, however, were prepared to relinquish the convention of unjustified setting. The American Institute of Physics (AIP), changed from Monotype to typewriter composition in the 1950s to make optimum use of the typewriter's capability - 'one font in one size with fixed "leading" but that could be fitted with a special attachment that included all the special characters needed to compose scientific papers':

There was some concern that physicists would object to the appearance of a typewriter-composed page with its typo graphic imperfections, unjustified margins, and limited number of type fonts. Experience has shown, however, 
that the quality we produce is acceptable to the majority of physicists, for whom accuracy and speed are far more important'. (Marks and Metzner 1973: 73)

Most typists would have accepted ragged-right setting without much ado. Though some would have acquired the relevant skills to justify lines, the additional time required to do this would have been a deterrent in everyday work. For most people, though, ragged-right was what happened when you used a typewriter, and they would have encountered it in everyday typewritten documents. As Robin Kinross (2002: 289ff) has pointed out, this is likely to have contributed to the general acceptance of unjustified setting. Indeed, in 1952, Herbert Spencer asserted in Design for business printing that readers did not notice the difference; he introduced a page of unjustified setting in a book that is set justified and challenged his readers to have noticed the change.

\section{Hierarchy and structure: 'display and setting out'}

Authors of typing manuals focussed on centring and capitals (of headings and titles in particular) to represent formality and authority. Writing in 1902, for example, Morton (1902: 35) noted:

Title headings require a certain amount of display, or setting out, and, by exercising a little ingenuity, very effective results can be produced. The chief item in the heading should be typed in capitals, and the whole should occupy a central position over the writing beneath. If the heading consists of not more than one or two words of average length, it is as well to divide the letters by spacing after each, with a double or treble space between each word, ...

He went on to illustrate how 'setting out' might be enhanced by ornament and space. The acceptability of such conventions stemmed from typesetting practice in book and similar kinds of printing. Producing top-quality centred display work was regarded as a specialist skill and not something to be rushed into: 'This kind of typing not only requires great patience but time must be spent in making the necessary calculations and in balancing the headings to the best advantage.' (Walmsley and Walmsley 1929: 75). The 'how to' in Pitman's typewriter manual is long and detailed, and many manuals show typists' handwritten workings out of the spaces that they need to leave before typing a heading so that it appears centred on the page, and there are endless exercises to be done to foster efficiency (Pitman 1897: 24-6). Trainees learned the art of 'display' which was closely aligned with 'taste': 
Taste in typewriting is almost entirely limited to display. This is a technical term which may be defined as being concerned with the most pleasing distribution of typewritten matter over the paper on which it is to appear. (Pitman 1897: 24) 'Artistic setting out' was another phrase used to describe display work. along with an assumption that this for some was a 'natural gift' and that others might acquire it through 'careful study of good typewritten models and of high-grade printed matter' (Walmsley and Walmsley 1929: 75). Walmsley and Walmsley continued: 'Free lessons may be taken by studying the bills posted on public hoardings. Printers are, or should be, masters of the art of displaying'. ${ }^{15}$ Many typing manuals contained exercises for creating borders and decorative elements for insertion into the text using characters and character combinations (see examples in Kostelnick 1994: 106), and that heralded what is now known as 'typewriter art' (see Tullet et al 2014). Competence in centred typing, and display, was ratified through success in typing exams, which affirmed its acceptability and promoted resistance to change by typists.

Centring and whole word capitalisation were advocated in the manuals until the 1970s when, with acceptance of the 'semi-blocked' and 'blocked' styles for setting out correspondence, display no longer referred to only centred typography. This was noted by Edith Mackay: “"Display” does not imply that the work must be centred. First-class display work can be produced by use of both the centred and blocked style of layout.' (1977: 61). By the 1970s most of the key typing manuals recommended the blocked or semi-blocked styles of layout because they were more efficient: centring headings and titles on a typewriter took time because it involved counting characters and aligning the carriage at the correct starting point. Efficiencies gained through use of ranged-left setting interested researchers James Hartley and Peter Burnhill in the 1970s, in the context of typing tables:

We would argue that the centring of items is irrational and time-consuming, both for typists and for printers, and that it would be more economical and rational if both text and tables were set 'ranged-left' or 'unjustified'. (Hartley and Burnhill 1975: 39)

They ran a series of tests in which typists were timed when typing centred and rangedleft versions of a simple and complex table and found that typists produced ranged-left tables more quickly and with fewer errors. They noted that when they centred text typists worked with the 'rules of thumb' they had been taught, and that while typists acknowledged that ranged-left tables were easier to do 'they did not look as nice'. This supported the view that typists' training strongly influences their opinions about visual organisation and consequently about what is 'correct'. Such views were prevalent 
beyond office work and centred text remained a visual attribute that many typists and lay people associated with formality, authority and correctness.

For trainee typists, along with centring, the 'art of display' included making the structure of a text clear - whether a legal document, specification or a commercial letter and the rules in the typing manuals provided a toolkit for structuring and articulating text. Typists put this into practice by copying handwritten material using the limited flexibility and character set of the typewriter to visually translate the handwriting so that its structure and meaning was clear. The prescribed hierarchical treatment - within constraints of machine with black ribbon only - in order of importance was as follows:

$\underline{\text { S A A E D CAPS UN DERLINE D }}$

S P ACE D C A P S

CAPS UNDERLINED

CAPS

Upper lower underlined

Upper lower

This system for denoting hierarchy appeared in most major typing manuals and quickly became standard and conventional practice until well into the twentieth century. Centring and using capital letters were regarded as correct and appropriate for posters and other documents produced by lay people. The rules became well established: in the 1960s, for example, The design for forms (HMSO 1962: 51), guidance for civil servants working in government departments, recommended and illustrated a similar set of principles.

\section{Differentiation of elements in the text: the underscore and the bi-chrome ribbon}

Typing manuals are a source of information for the rules and principles of the articulation of text at a micro level, which are referred to by printers as 'house style'. Many of the rules presented in typing manuals followed those in printers' style manuals, though with considerable time lag, and as many were produced in numerous editions, the dates of changes can be recorded. In relation to the preferred form of writing the date, for example, the form 17 March 1967 was not prescribed as the correct form in typing manuals until the 1970s, whereas many printers' house style manuals prescribed this form from the 1940 (Walker 2001: 101-2). ${ }^{16}$ In this context, the 
manuals provide a rich resource for considering the role of prescription in the evolution of written language.

In typeset text composition, bold and italic variants, and changes of typeface and type size are used for emphasis and differentiation, and there are rules associated with their usage. On a standard typewriter, capital letters and underlining, sometimes combined with a second colour or additional horizontal space were typically the means through which words, phrases and larger components of text could be differentiated or emphasised. Underlining was and remains a characteristic visual attribute of typed text, despite being a time-consuming procedure. It necessitated typing the words normally and then reversing the horizontal escapement so that the underscore could be typed below the relevant characters. Rules for the use of the underscore reflected prescription and use of italic in print: for titles of books, newspapers and plays; for foreign words and for emphasis (Morton 1902: 48; Pitman 1897: 83). In commercial correspondence it was the preferred treatment for subject headings in business letters, and capitals and the underscore were used for strong emphasis in, for example, legal and insurance work (Figure 5).

Typewritten material, on the whole, was monochrome, but some document types typically required the used of a second colour to fulfil a particular function. Typing in colours other than black involved either the use of coloured carbon paper, special twoor three-colour attachments, or a bi- or tri-chrome ribbon. Red, the preferred second colour, was recommended for emphasis and particular words in a text, and was referred to in Pitman's typewriter manual in 1897 as 'variegated typewriting' (Pitman 1897: 33). ${ }^{17}$ In the typing of plays, for example, underlining in red was prescribed to denote non-spoken elements, such as stage directions shown in Figure 6. However, as affirmed in Pitman's typewriter manual (1897: 56), in recognition that it was time consuming to do, typists were encouraged to do the red ruling with a pen or pencil - a pragmatic solution. Later typing manuals proposed that when a typewriter was fitted with a red-black bi-chrome ribbon, the non-speaking parts should be typed in red (with no underlining) - an example of simplicity of operation changing conventional practice.

\section{Tabular matter}

Tabular matter was probably the most typographically complex work that typists encountered, and where the capabilities of the typewriter were pushed to their limit, 
even if the machine was fitted with a tabulator - 'a device for moving the carriage to any predetermined position ... it is a great time-saver in the typing of tabular matter' (Walmsley and Walmsley 1929: 86). Most manuals went into considerable detail about the mechanics of setting the tabulator stops. ${ }^{18}$ But few mention matters of style. When they do, references to layout are vague: 'The work should be balanced and judicious use made of line and margin spacing' (Walmsley and Walmsley 1929: 87). Some manuals contained facsimile examples of tabular work with headings centred over columns, leader dots and horizontal and vertical rules. Most of the manuals provided instructions to rule lines in red once the table has been typed, recognising the challenge of producing horizontal and vertical lines using the underscore and the $\mid$ character (Morton 1902: 100). However, in the tabular arrangement shown in Figure 7 the typist was advised to fold the paper and insert it into the machine sideways to type the vertical rules (and presumably the rotated column heading). Such examples emphasise both the cumbersome nature of the machine as well as fiddly and inventive ways to overcome challenges. Tabular work was time-consuming and inefficient (as noted earlier with reference to headings) but as tabular work featured in much commercial and office work it was a necessary skill - the complexity of the texts that typists had to deal with is demonstrated through the handwritten examples that typists were asked to translate into typed form as part of their training. ${ }^{19}$

\section{A contribution to the history of graphic language and document design}

Typewriters have made a significant contribution to the history of graphic language and document design, equivalent to the impact of desktop publishing (DTP) in the late twentieth century (see, for example, Walker 2001; Colman 1988; Kostelnick 1990). Those who trained as typists to be able to have careers in commerce, business or the Civil Service became 'lay typographers' acquiring skills training in the visual organisation of everyday documents that reflected elementary principles of typography, albeit at a basic level, and as we have seen, those parts of the publishing industry that embraced typewriter composition in the 1960s employed typists in the role of compositor. Typists, who had acquired specialist knowledge about the visual organisation of language through their training, made documents that reflected the limitations of the machines that produced them. The manuals that codified typing practice and skills acquisition, therefore, had considerable influence on everyday graphic language, which thereby shaped readers' views of what were the 'correct' conventions to use for articulating text. These became so well-established that in the 
late 1980 s and 1990 s when DTP became widespread, books such as The Mac is not a typewriter (1990) and Collier's rules for desktop design and typography (1990) emphasised the difference between typesetting and typing conventions to lay users of DTP.

The availability of typewriters and their relative ease of use also meant that unskilled typewriter composition predominated in community, underground and activist publishing in the 1970 s and early 1980 s, not least because it could be combined with reproduction by stencil-duplicating - a cheap and easy way of making multiple copies (Treweek and Zeitlyn 1983). In this context typewriter users were not bound by the rules and principles presented in typing manuals. The documents they produced were done so with minimal means in terms of skill and technological constraints, and that resulted in a particular visual style. See, for example, Triggs 2006 with reference to Punk zines, and Walker 2001: 73, for examples of community-produced flyers.

\section{A contribution to typographic education}

Herbert Spencer was one of the first to acknowledge in print that typewriters were a useful and relevant component of a designer's toolkit. In Design for business printing he drew a connection between typewriting and unjustified setting in support of his arguent that asymmetric typography was the most suitable for business printing.

Typewritten matter is always asymmetrical - on the typewriter lines cannot conveniently be centred or forced to an even length - an only on asymmetrically arranged stationery and forms can typewritten matter be accommodated, as it should be, as an integral part of the design. (Spencer 1952: 37)

He used letterhead design as an example. When typewritten letters were the norm it was regarded as good practice to position the pre-printed elements of a letterhead so that it was easy for the typist to match their alignment across or down the page, so that a date could be typed directly underneath the sender's address, or a reference next to its cue (Spencer 1952: 39-40). The fine horizontal increments of typesetting, therefore, had to be synchronised with the much coarser horizontal increments of the typewriter, and the type body sizes and line spacings had to be synchronised with the increments by which the typewriter platen advanced. Combining pre-printed matter and typewriting in this way meant understanding the measuring systems of both print and typewriters, and working out where the typewriter's 10- and 12-pitch increments coincided with traditional printers' increments to determine convenient positions for aligning text. ${ }^{20}$ 
Norman Potter in his inspirational What is a designer (first published in 1969, revised and extended in 1980), reinforced the value of typewriters in an educational context. He advised students:

Come to terms with the graphic potential of a portable typewriter. . Touchtyping is a skill worth having but its possession may entail bad graphic habits: some training courses are notorious inn this respect. Two-finger typing is still faster than handwriting (with a bit of practice) so for layout purposes and occasional use, this is an acceptable alternative to the proper thing. The typewriter is good for controlled experimentation because there are mechanical they include, of course, a built in asymmetry deriving from the 'ranged-left and open ended nature of the platen movement (usually ignored by typing instructors). (Potter 1980: 132)

He suggested that typewriters provided a quick way to think about different ways of signalling the start of a paragraph, or to structure text in reports and other documents where 'clear graphic sequence' is important. Michael Twyman (1981) extended this notion in his teaching as a means of explaining the numerous ways that headings and sub-headings could be treated. In Twyman's system of notation lower-case 'o' was used to represent 'main text' and ' $x$ ' used to denote headings. Capitals of each of these added a further level of differentiation, and horizontal space - for indentation or separation of elements were used in the usual way. Used in this way typewriters provided a quick and easy way to make schematic representations of typographic configurations. Use of the system was extended by Paul Stiff who used it in lectures to students to explain the variety of ways that tabular matter could be arranged. ${ }^{21}$

Typewriters and their limitations as a method of composition had impact on students of typography and graphic communication who, as part of their education in design for reading, benefited from knowing about the graphic capability of composition systems and designing within their limitation and constraints as a result. In this context the very simple capability of typewriters drew attention to the importance of structure and hierarchy. Designing within technological constraints is something that many typographers welcome and value as a means of getting to the essence of a particular communication challenge - how can text be structured with just one typeface in one size, and with crude spatial variants. When I was an undergraduate in the 1970s, manual typewriters were treated as a method of character assembly alongside handcomposition in metal type, Monotype and Intertype composition - and indeed handwriting. Student projects often involved setting out text in three or four different 
ways to learn how to articulate text using space and the means of graphic differentiation offered by the different methods of composition. ${ }^{22}$ Using typewriters revealed that it was possible to produce documents that reflected sound typographic practice and demonstrated how the graphic capabilities of a typewriter related to other methods of assembling text. This drew attention to the value of designing within minimal means, emphasising the importance of the clear articulation of the structure of a text through the use of space and available graphic attributes. It highlighted the job of the typographer to understand that different graphic and spatial means can be used for emphasis, differentiation, separation and connection, quotation, interpolation and so on within a text (cf Potter 1980: 132; Walker 2001: 85-125). Such functions within a text can be fulfilled, albeit in different ways, whatever the composition system being used.

In conclusion, typewriters are a somewhat neglected part of typographic history - their technical limitations do not offer the beauty of form and subtlety of spacing that typographers yearn for. Yet, as we have seen, their use as a design tool has been recognised and exploited to good effect by many twentieth-century designers and educators. Typing manuals deserve to assume a key position in the history of graphic communication due to their impact on the visual organisation of graphic language and its dissemination. They are a rich and largely undiscovered source of information about rules for organising graphic language, particularly relevant because of their connection to everyday communication. For many, though, it is the endearing technical clunkiness of typewriters that is fascinating - as it was for archy (marquis 1961: 57-58):

colon the fact is that

the mechanical exigencies of

the case prevent my use of

all the characters on the

typewriter keyboard period

capital i apostrophe m

doing the best capital

i can under difficulties semi colon

In the next chapter Mehitabel unlocked the shift key: CAPITALS AT LAST.

\section{References}

Adler, Michael. 1973. The writing machine: a history of the typewriter. London: George Allen \& Unwin.

Bartram, Alan. 1962.'Typewriter typefaces’, Typographica, 6: 42-59. 
Beeching, Wilfred. 1974. Century of the typewriter. London: Heinemann (2nd edn 1990 published by the British Typewriter Museum, Bournemouth.

Chiswick Press. 1913. A few notes on the style and customs of the Chiswick Press. London: Chiswick Press.

Collyns, Edith. 1909. The typists' manual; a text-book for commercial students. 7 th edn, Manchester: John Heywood Ltd.

Colman, Helen. 1988. 'The graphic translatability of text in relation to desktop publishing'. Unpublished undergraduate dissertation, Reading, Department of Typography \& Graphic Communication

Crellin, Vivien H. 1982. 'Introduction' in Writing by rote: the rise and fall of copperplate handwriting seen through school copy-book and exercise books from the nineteenth century, Reading: Department of Typography \& Graphic Communication.

Garland, K. 1966. Graphics handbook. London: Studio Vista.

Hartley, James and Peter Burnhill. 1975. 'On the typing of tables', Applied ergonomics, 6(1): 39-42.

Heelis, Frederick. 1931. Pitman's business typewriting, London: Sir Isaac Pitman \& Sons: 65 .

HMSO. 1962. The design of forms for government departments. London: HMSO.

Jamison, Martin (1998) 'The changeable course of typographic justification', Scholarly Publishing, 29, 2: 71-86.

Keeler, G. A. 1904. 'Style, uniformity and 'form' in commercial typewriting'. Series of articles in Pitman's journal, 1 October - 5 November.

Kinross, Robin. 2002. Unjustified texts perspectives on typography. London: Hyphen Press.

Kostelnick, Charles. 1990. 'Typographical design, modernist aesthetics, and professional communication', Journal of Business and Technical Communication. 4(1): 5-24.

Kostelnick, Charles. 1994. From pen to print: the new visual landscape of professional communication. Journal of Business and Technical Communication. 8(1): 91-117.

Mackay, Edith. 1977. The typewriting dictionary. London: Pitman.

Mares, George Carl. 1909. The history of the typewriter: being an illustrated account of the origin, use and development of the writing machine. London: Pitman

Marks, Robert H. and A. W. Kenneth Metzner. 1973. 'Typewriter composition cuts journal costs, speeds publication', IEEE Transactions on Professional Communication, $P C-16(3): 73-79$.

marquis, don. 1934. archys life of mehitabel. London: Faber \&Faber. 
McIntosh, A. 1965. Typewriter composition and standardization in information printing. Old Woking: The Gresham Press.

Morton, Arthur. E. 1907. Modern typewriting and manual of office procedure, $4^{\text {th }}$ edn London: The Smith Premier Typewriter Co. and Sir Isaac Pitman \& Sons Ltd.

Morton, Arthur. E. 1902. Modern typewriting and manual of office procedure. London: The Smith Premier Typewriter Co.

Norrish, Patricia. 1987. The graphic translatability of text, British Library R \& D Report 5854. Reading: Department of Typography \& Graphic Communication.

Pitman. 1897. Pitman's typewriter manual: a practical guide to commercial, literary, legal, dramatic and all classes of typewriting work. 2nd edn. London: Sir Isaac Pitman \& Sons.

Potter, Norman. 1969. What is a designer: education and practice. London: Studio Vista.

Potter, Norman. 1980. What is a designer: things, places, messages. Reading: Hyphen Press.

Richards, G. Tilgheman. 1964. The history and development of typewriters. London: HMSO

Southall, Richard. 1984. 'First principles of typographic design for document production', TUGboat 5(2): $79-90$.

Spencer, Herbert. 1952. Design in business printing. London: Sylvan Press.

Stiff, Paul. 1996. 'The end of the line: a survey of unjustified typography, Information Design Journal, 8(2): 125-52.

Stiff, Paul. 2005. 'Some documents for a history of information design', Information Design Journal + Document Design, 13(3): 216-28.

Sylvester, A. J. (1913). Underwood typewriter manual. London: Sir Isaac Pitman \& Sons.

Tschichold, Jan. 1935. Asymmetric typography London: Faber and Faber (Translation of Typographische Gestaltung, Basle, 1935)

Treweek, Chris and Jonathan Zeitlyn. 1983. The alternative printing handbook. Harmondsworth: Penguin.

Triggs, Teal. 2006. 'Scissors and glue: punk fanzines and the creation of a DIY aesthetic', Journal of Design History, 19(1): 69-80.

Tullet, Barrie; John Dowling and Jodi Simpson. 2014. Typewriter art: a modern anthology. London: Laurence King

Twyman, Michael. 1981. 'Typography without words', Visible Language, 15(1): 5-12.

Tyler, Cyril. 1946. Organic chemistry for students of agriculture (and allied subjects), London: George Allen and Unwin. 
Walker, Sue. 1984. 'How typewriters changed correspondence: an analysis of prescription and practice'. Visible Language, XVIII (2): 102-117.

Walker, Sue. 2001. Typography and language in everyday life. Harlow: Pearson.

Walker, Sue. 2013. Book design for children's reading. London: St Bride Foundation.

Walmsley, William and Elizabeth Walmsley. 1929. Pitman's commercial typewriting: a progressive course in touch typewriting arranged in the rhythmic method, London: Sir Isaac Pitman \& Sons Ltd.

Yates, Joanne and Wanda J. Orlikowski. 1992. 'Genres of organizational communication: a structurational approach to studying communication and media', The Academy of Management Review, 17(2): 299-326. 
${ }^{1}$ An early association of 'modern' with the typewriter was in the title of Arthur E. Morton's Modern typewriting and manual of office procedure, London: The Smith Premier Typewriter Co. and Sir Isaac Pitman \& Sons Ltd, first published in 1902. The term is used here to refer to the ubiquitous use: 'in every department where writing is done'; and to the method through which typing was 'systematically taught and properly learned' p. 5.

2 Paul Stiff cites Spencer's use of the term 'utility printing' as the first item in his timeline: 'Some documents for a history of information design' (Stiff 2005: 227). See also Kostelnick (1994) in relation to business and technical communication.

${ }^{3}$ See the 'Typewriter composition' supplement in McIntosh (1965). This provides a useful illustrated account of typewriter compositionin the 1960s, including comparisons of the typographic features of the IBM Executive, Justowriter, Varityper and IBM 72.

${ }_{4}^{4}$ Mares (1909) is an extensive technical account of different kinds of typewriter in the early years of its development. Richards (1962) is an excellent general, brief account; Adler (1973) and Beeching (1974) provide accessible historical accounts. Recent growing interest in typewriters has led to numerous websites, such as The Classic Typewriter Page

http://site.xavier.edu/polt/typewriters/index.html and The Virtual Typewriter Museum http://www.typewritermuseum.org/index.html

5 The Civil Service hand was developed through collaboration between Prime Minister Palmerston and Vere Foster - who developed a script that was a rounder, more upright and bolder version of copperplate, and better suited to the speed and clarity required in government work. (Crellin 1982: 9-10).

${ }^{6}$ The second edition of $A$ manual of the typewriter published in 1897 was entitled Pitman's typewriter manual. A practical guide to commercial, literary, legal, dramatic and all classes of typewriting work.

See Walker 2001: 195-8 for a select bibliography of typing manuals and articles about typing from 1876 to 1981 . This listing of over 50 titles and the numerous editions that they were published in underpins a detailed survey of rules for house style and the layout of correspondence (see Walker 1984, 2001) Good holdings of typing manuals can be found in the Bodliean Library, Oxford and the Julie Peverett Typing Collection at the University of Reading.

${ }^{8}$ See Bartram 1962: 42-59. Bartrams's selection of typewriter faces includes those produced for typewriters with proportional spacing, used in IBM machines (and therefore widely available) from around 1940.

${ }^{9}$ Even as late as the mid-1970s, Edith Mackay (1977) noted that leaving one space after a full-point would be penalized in typing examinations. Most designers (and design students) at this time would have regarded one space after a full point as 'correct'.

${ }^{10}$ See Walker 2013. Even in the 1930s Jan Tschichold felt the need to write: 'There should be no extra space after full points.' (Tschichold 1967: 40).

11 As Paul Stiff (1996: 129) remarked: 'And unjustified setting is still associated with relatively ephemeral and informal kinds of discourse. By contrast, justified setting is commonly assumed to be the norm for those document genres associated with formality and permanence.'

12 For example, the Hammond typewriter in the USA, which in the 1920s was renamed the Varityper. With such machines it was theoretically possible to produce a justified right-hand edge. ${ }^{13}$ Some attempts to produce justified lines were rather more extreme: 'Vogeltype Aligning Paper' that was developed in the 1930s in the USA by Joseph Spielvogel, and involved typing on stretchable paper so that short lines could be cut, pulled to the right length and stuck down again http://oztypewriter.blogspot.co.uk/2011/04/typesetting-with-typewriters-literary.html US patent Art of Reproduction 2177539, 1935 http://www.freepatentsonline.com/2177539.html ${ }^{14}$ The note, written by Michael Twyman, recalls a conversation he had with Cyril Tyler about the production of the book. A copy is found in the A. F. Johnson Collection, Department of Typography \& Graphic Comunication, University of Reading.

15 The Walmsleys were prolific typing manual authors. They made occasional reference to the difference in character sets available to printers and to typists. For example: 'Of course, the printer has the advantage over the typist, inasmuch as he has an almost unlimited number of styles and 
sizes of type with which to work, while the typist is limited to the use of one style and one size'. Walmsley \& Walmsley 1929: 75.

16 Hart's rules for compositors and readers at the University Press, Oxford recommended the form 16 May 1921 in the 1925 edition (Author 2001: 106; and 101-2), though the Chiswick Press did so in 1913 (Chiswick Press 1913).

17 Typewriter inks were of two kinds - for permanent records and for copying, that is, for when copies of documents had to be inserted into a 'copying book' or 'letter book' (Morton, 1902: 89-90). Some kinds of official work required other colours (such as greenish blue for copies of government documents (Morton 1902: 17)

${ }^{18}$ For example, Sylvester 1915: 47-53; Morton 1902: 101-3.

${ }^{19}$ Pat Norrish (1987: 2) used the term 'translatability of text' to refer to: 'the presentation of material, originally produced in a system with one range of resources, on one in which the range is different [in terms of character set and spatial flexibility]; and the production of complex material on systems designed to handle less complex material.'

20 'Pitch' in this context referred to the number of characters per inch.

${ }^{21}$ See the example in in Author 2001: 175.

22 Michael Twyman (1982: 2-22) used the terms 'intrinsic' and 'extrinsic' to refer to features that reside in the characters themselves, such as size, style and weight of letters (intrinsic) and what can be done to those characters by manipulating the space around them (extrinsic). 


\section{Captions}

Figure 1

Styles of type in common use at the beginning of the twentieth century. 'Vertical' illustrated at the bottom of the list was not included in later editions indicating that it was no longer expected that typed documents reflected the previous method of composition (Morton 1902: $34)$.

Figure 2

Examples of 'special signs and characters' that are made by combining characters: 'One character can be typed over another by holding down the space bar whilst the two characters are struck in succession, or by use of the back spacer key.' (Heelis 1931: 65)

Figure 3

Recommended uses for single, double and treble line spacing. (Morton 1902: 23)

Figure 4

Spread and detail of opening paragraph indentation Tyler (1946).

These examples show the justified lines that would have resulted from a second typing on a Varityper. Superior and inferior figures were added by hand and the formulaic lines drawn by hand by an artist working on gridded paper. The author decided on the large paragraph indent and, most unusually, a double-line indentation at chapter openings. (As reported to Michael Twyman, in conversation with Cyril Tyler, in the 1970s).

Figure 5

Facsimile example for an Insurance Office Report showing prescribed use of capital letters and underlining. (Pitman 1897: Exercise XXXVI)

Figure 6

Detail from plate XIV showing use of red underscoring to denote non-spoken parts in a play. (Pitman 1897)

Figure 7

Example of a table with vertically typed headings. To execute this, typists were advised to fold the paper and insert it sideways into the machine. (Morton 1902: 130) 